\title{
A Prospective study of etiology and outcome of Preterm Labour in a Rural Medical College
}

\author{
Sunita Sudhir $\mathbf{P}^{1}$, Mishra $\mathbf{S}^{2}$ \\ ${ }^{1}$ Dr Sunita Sudhir P, Associate Professor, ${ }^{2}$ Dr Sunita Mishra, Professor, both authors are affiliated with Department of \\ Obstetrics and Gynaecology, Kamineni Institute of Medical Sciences, Narketpally, Telangana State, India.
}

Address for Correspondence: Dr Sunita Sudhir P., Associate Professor, Department of Obstetrics and Gynaecology, Kamineni institute of medical sciences, Narketpally, Telangana State, India, E-mail: sunitadr@rediffmail.com

\begin{abstract}
Introduction: Preterm birth is a major problem in developing countries contributing significantly to perinatal mortality. Preventing preterm labor is still a great challenge in modern obstetrics .Every year an estimated 15 million babies are born too early (more than 1 in 10 babies are preterm). 1 million neonates dies each year due to complication of preterm birth. Many who survive face a life time of disability. Aim \& Objective: To study the etiological factors and to assess the Neonatal Mortality and Morbidity associated with preterm labor and delivery. Methods: This prospective study was conducted from December 2014 to September 2015 in rural medical college where 107 antenatal women admitted with threatened preterm labor with or without rupture of membranes were followed till delivery and discharge. Gestational age at onset of preterm labor, associated risk factors, response to Tocolytics, Gestational age at delivery, and neonatal outcome were recorded and analysed. Results: Pregnancy Induced Hypertension, Anaemia, Infections, Oligohydramnios, were the commonest causes of preterm deliveries. Neonatal morbidity and mortality was less in steroid covered group. Birth asphyxia, Respiratory Distress Syndrome, Hyaline Membrane Disease were the commonest causes of morbidity. Respiratory Distress Syndrome was significantly reduced in those who were on steroid cover. Conclusion: There is a high incidence of preterm labor and preterm births in our set up. Infection and anaemia are important factors which can be prevented. Prolongation of delivery for 48 hrs by giving Tocolysis for getting the benefit of betamethasone coverage reduces morbidity due to RDS.
\end{abstract}

Key Words: Preterm Labor, Preterm Delivery, Uterine Tocolysis, Preterm Neonate.

\section{Introduction}

Preterm birth is a major problem in developing countries contributing significantly to perinatal mortality [1]. Preventing preterm labor is still a great challenge in modern obstetrics. Every year an estimated 15 million babies are born too early (more than 1 in 10 babies are preterm). Approximately1 million neonates dies each year due to complication of preterm birth. Many who survive face a life time of disability [2].

Nearly half of the preterm births are preceded by pre term labor. The etiology of preterem delivery is unclear but is likely to be complex and influenced by genetics and environmental factors. Women with previous preterm birth are at increased risk of subsequent preterm birth delivery [1]. We need to be aware that Pre Term Labor (PTL) is not a disease, but an event which may result from single or multiple independent or interdependent

Manuscript received: $4^{\text {th }}$ December 2016

Reviewed: $12^{\text {th }}$ December 2016

Author Corrected: $22^{\text {nd }}$ December 2016

Accepted for Publication: $31^{\text {st }}$ December 2016 pathways [1] Preterm labor is often the final step in the multi-factorial process [3].

Preterm labor can be either iatrogenic or spontaneous, iatrogenic is the one which is induced by the obstetrician to terminate the labor with specific indications, where as spontaneous is the one which occurs in spite of best efforts to prolong the pregnancy, $80 \%$ of all the preterm labor fall in this category [4]. As preterm labor causes considerable morbidity and mortality in terms of neonates and mother and no single factor is solely responsible for pre term labor and delivery. This study was aimed at identifying the common factors responsible for pre term labor delivery and its outcome after possible intervention

\section{Aims and objectives}

1. To study the etiological factors of preterm labour and delivery.

2. To study the neonatal mortality and morbidity associated with preterm delivery.

Available online at: www.medresearch.in 44 | P a g e 


\section{Materials and Methods}

Study design: Prospective Observational Study

Place of study: Department of Obstetrics and Gynecology

Kamineni Institute of Medical Sciences, Narketpally.

Period of study: Dec 2014 to May 2015

Sample size: 107

\section{Inclusion criteria:}

- All the patients admitted with preterm labor pains.

- All patients who were admitted and induced labor in preterm period.

\section{Exclusion criteria:}

- Patients of gestational age $<28$ wks.

- Patients of gestational age 37 wks and above.

Methodology: This was a prospective study conducted in the Department of Obstetrics and Gynecology of a rural medical college from December 2014 to September 2015. 107 cases of preterm delivery were studied. All patients

\section{Original Research Article}

enrolled in the study were admitted and cause for preterm labor analyzed. Tocolytics were given in cases where immediate delivery was not indicated. Cases under conservative management were treated with appropriate antibiotics, fluid therapy. In cases with mild to moderate oligohydramnios amino acid infusion and fructodex was given. Betamethasone 2 doses of $12 \mathrm{mg}$ were given $24 \mathrm{hrs}$ apart. Single dose of Betamethasone was given where immediate delivery was indicated. In those cases where termination of pregnancy was indicated, induction of labour was done and cases were managed by either vaginal delivery or emergency LSCS depending on the indication.

Immediately after delivery all the babies were attended by the pediatrician, APGAR score at 1 minute and 5 minute was noted, weight and sex of the baby recorded, depending on the condition, neonates were shifted to NICU and managed accordingly. Normal healthy neonates were shifted on to mother's side.

\section{Results}

In our study we observed that out of 107 cases, In 45(42.05\%) cases conservative management was planned where antibiotics and tocolytics were given. In 29 cases pregnancy was prolonged for 2 days and until then betamethasone doses were given. In 6 cases pregnancy could be prolonged for a week, in 4 cases pregnancy could be prolonged for 2 weeks, in $6(5.6 \%)$ cases pregnancy could be prolonged to the expected date of delivery (EDD). Delivery on the day of admission was observed in 62 cases $(57.94 \%)$, out of which $10(10 \%)$ cases had preterm Intra Uterine Death (IUD) where termination was indicated, $4(3.73 \%)$ cases had spontaneous preterm still birth. Rest 48 cases had live births where only a single dose of steroid could be given.

Analysis of etiological factors revealed it to be multifactorial they were either acting singly are in conjunction with other factors. eg. anaemia with PIH, Oligohydramnios or anaemia with infection.

Other Underlying risk factors like low socio economic status (SES), Smoking, unhealthy lifestyle, maternal age, were indirectly associated with anemia and PIH. Fetal outcome was studied in all cases admitted with preterm births, out of the 107 cases admitted with preterm gestation, 10 cases had IUD, 4 cases had still birth due to severe preeclampsia. Out of 93 $(85.7 \%)$ live births. $14(8.5 \%)$ healthy babies were shifted to the mother side. 79 babies required NICU admission, out of which 14 babies were put on Ventilatory support and rest 65 babies were kept under observation.

Out of 79 babies in NICU 70 babies recovered and were discharged, 9 babies died during neonatal period. Cause of death in the neonatal period was Respiratory Distress Syndrome (RDS) in 4 babies, Hyaline membrane disease (HDM) in 2 babies and Sepsis in 3 babies.

Table-1: Pregnancy Duration.

\begin{tabular}{|c|c|c|}
\hline No. Of days pregnancy prolonged & $\begin{array}{c}\text { Number of cases } \\
\text { N (107) }\end{array}$ & Percentage \\
\hline Two days & 19 & $17.75 \%$ \\
\hline 1 week & 16 & $14.95 \%$ \\
\hline 2 week & 4 & $3.73 \%$ \\
\hline Upto Term & 6 & $5.6 \%$ \\
\hline Delivery on the day of admission & 62 & $57.94 \%$ \\
\hline Total & $\mathbf{1 0 7}$ & $\mathbf{1 0 0 \%}$ \\
\hline
\end{tabular}


Table-2: Risk Factors for Preterm Labor.

Original Research Article

\begin{tabular}{|c|c|c|}
\hline Etiological factor & $\begin{array}{c}\text { No of cases } \\
\mathbf{N = 1 0 7}\end{array}$ & Percentage \\
\hline PIH & 44 & $41.12 \%$ \\
\hline Anemia & 38 & $35.55 \%$ \\
\hline Oligohydramnios & 33 & $30.84 \%$ \\
\hline Vaginitis & 29 & $27.10 \%$ \\
\hline UTI & 14 & $13.08 \%$ \\
\hline Abruption of Placenta & 9 & $8.41 \%$ \\
\hline PROM & 8 & $7.47 \%$ \\
\hline 2 Previous LSCS & 9 & $8.41 \%$ \\
\hline Placenta Previa & 3 & $2.8 \%$ \\
\hline HELLP Syndrome & 2 & $1.86 \%$ \\
\hline Twins & 2 & $1.86 \%$ \\
\hline Polyhydramnios & 1 & $0.9 \%$ \\
\hline 1 Previous LSCS & 1 & $0.9 \%$ \\
\hline
\end{tabular}

Table-3: Multifactorial Etiology

\begin{tabular}{|c|c|}
\hline Factors & No. of cases \\
\hline PIH + Anaemia+ oligohydraminos & 19 \\
\hline PIH + Anaemia & 27 \\
\hline Anemia + UTI + Vaginitis & 22 \\
\hline UTI + Vaginitis & 26 \\
\hline Vaginitis + PROM & 5 \\
\hline PIH + Abruption & 8 \\
\hline Previous LSCS + Anaemia & 32 \\
\hline Twins + PIH & 2 \\
\hline
\end{tabular}

Table-4: Fetal Morbidity and Mortality

\begin{tabular}{|c|c|c|c|c|c|c|}
\hline & $\mathrm{N}=93$ & \multicolumn{5}{|c|}{$\mathrm{N}=79$} \\
\hline \multirow[t]{6}{*}{ NICU admission } & \multirow{6}{*}{79} & \multirow{2}{*}{\multicolumn{2}{|c|}{ Recovered }} & \multicolumn{3}{|c|}{70} \\
\hline & & \multirow{4}{*}{\multicolumn{2}{|c|}{ Neonatal Death }} & \multirow{4}{*}{9} & Rds & 4 \\
\hline & & & & & HMD & 2 \\
\hline & & & & & SEPSIS & 3 \\
\hline & & & & & TOTAL & 9 \\
\hline & & \multicolumn{2}{|c|}{ Total } & \multicolumn{3}{|c|}{79} \\
\hline $\begin{array}{l}\text { Babies shifted to mother } \\
\text { side }\end{array}$ & 14 & & & & & \\
\hline Total Live Births & 93 & Still Birth 4 & $\begin{array}{c}\text { IUD } \\
10\end{array}$ & & $\begin{array}{l}\text { al } \\
+10)\end{array}$ & 107 \\
\hline
\end{tabular}

Table-5: Neonatal Morbidity and Mortality in patients who received steroid and patients who did not receive steroid

\begin{tabular}{|c|c|c|}
\hline & Neonatal Morbidity (n=70) & Neonatal Mortality(n=23) \\
\hline $\begin{array}{c}\text { Steroid Uncovered Group } \\
(\mathbf{n}=\mathbf{6 2})\end{array}$ & $\begin{array}{c}43 \\
(61.4 \%)\end{array}$ & $\begin{array}{c}19 \\
(82.6 \%)\end{array}$ \\
\hline Steroid Covered Group (n=45) & 27 & $(4)$ \\
& $(38.6 \%)$ & $(17.3 \%)$ \\
\hline
\end{tabular}




\section{Discussion}

Infants delivering before 37 weeks are continuously rising from $11 \%$ in 1998 to $12.5 \%$ in 2003 , according to vital statistics in USA [5]. Incidence of preterm labor is showing an increasing trend due to factors like increased rate of assisted reproductive technology, increased rate of multiple pregnancies early and late procreation and better obstetric intervention the above table compares the incidence of preterm births and their trends in different countries. Among the developing countries India has high incidence of preterm labor

Trend Analysis: Increased trend of preterm birth and low birth weight has been in recent studies $[6,7]$.

Out of 107 cases of preterm deliveries, 62(57.9\%) of the cases had delivery on the same day of admission either spontaneous or induced depending upon the indication. ACOG committee in the year 2003 made a similar observation i.e., $30-60 \%$ of women presenting with preterm contraction go on to deliver prematurely [2]. Mc Pheeters et al observed that incidence of first time hospitalisation for preterm labor is $9 \%$ with only $38 \%$ delivering in their first episode [8]. In an analysis of 3728 deliveries in Singapore 571 (15.37\%) women who were anaemic at the time of delivery had higher incidence of preterm birth thus the results of several studies are consistent with an association between maternal IDA and greater risk of preterm delivery [3]. Scholl T.O. [12] noticed two fold increase in preterm lobor in patients with iron deficiency anemia. In our study out of the 107 cases of preterm delivery 38 (35.5\%) of cases had anaemia, 2 cases had HELLP syndrome. This study was done in a rural population where incidence of anaemia is high since adaloscent age other factors which could contribute to higher incidence of anaemia in our study were non compliance of iron and folic acid tablets during ANC period, and less than 3 years of gap between two pregnancies.

In the present study $44(41.12 \%)$ of the cases with preterm delivery had pregnancy induced hypertension (PIH), A study in African black women by Samadi AR et al [13] have found that preterm birth were almost 2 times more likely for women with PIH (OR-1.8; 95\% CI 1.5, 2.2) Compared with normal women.

From a POUCH study cohort (Pregnancy Outcome and Community Health) evidence of placental haemorrhage was significantly associated with preterm labor. Few studies have empirically demonstrated an association between subclinical evidence of haemorrhage in delivered placenta and preterm delivery by comparing preterm and term placenta [3]. In a prior work from the POUCH study, the microscopic haemorrhages' construct was found to be associated with both spontaneous and indicated preterm delivery $<35$ weeks [15]. In the present study $9(8.41 \%)$ cases had abruption and haemorrhage. Juliar Warner Gargon et al in his study concluded that sbruption and ploacental haemorrhage were associated with 2 - fold in increased risk of preterm delivery [14].

In the present study we found out that infection was one of the major etiological factor identified as cause of pre term labour in $35.6 \%$. UTI accounted for $8.5 \%$ of cases and vaginitis accounted for $27.1 \%$ of cases. According to Gonclaves et al [9] intrauterine infections are a major cause of preterm labor with or without intact membranes and account for approximately $25 \%$ of cases. Lamont [10] concluded that infection is responsible for preterm labour in $40 \%$ of cases. Wright et al [11] identified UTI as a significant risk factor contributing to $7 \%$ of preterm birth. In a study done at lucknow (UP) by Singh Uma et al [16] genitourinary infection is the second commonest cause of preterm delivery, ie (20.7\%), UTI was present in $8.4 \%$ and vaginitis was seen in $12.5 \%$ of cases. Apart from this Wright SP et al [11] found that smoking and multiparity were modifiable risk factors in pre term labor.

The WHO Reproductive health library (RHL); GENEVA WHO, Revised a document 15 Nov 2002[17], prophylactic antibiotic for inhibiting Preterm labor with intact membranes, the Cochrane review found that antibiotic treatment in women with pre term labor and intact membranes reduces chorioamnionitis / endometritis ( RR;0.74;95\% CI; 0.64 to 0.87 ) but has no effect on reduction in preterm births or adverse neonatal outcomes but they also mentioned that most trials from this review were conducted in developed countries and the same review says that in most parts of the sub-Saharan Africa reproductive tract infections (RTI) are highly prevalent and therefore the contribution of pre term birth is higher. The problem is compounded in the developing countries by poor resources allocation and low and late antenatal care attendance. Despite the negative results of the review there is a room for research in the developing country to determine the pattern of genital tract infection in pregnancy and establish local antibiotic policy [17]. In our study in $35 \%$ of cases we could prolong the pregnancy up to 36 weeks of gestation with tocolytics and antibiotics.

Review of several studies and meta analysis reports by $\mathrm{C}$ Hubinont confirms the efficacy of $\beta$ adrenergic receptor agonist, prostaglandin synthetase inhibitors and Atosiban for delaying delivery for 24-48 hrs [18]. 
In present study Neonatal morbidity in steroid covered group was $31 \%$ and steroid uncovered group was $76.3 \%$. This can be compared with a study conducted by Singh Uma et al [16] where they observed that neonatal morbidity in steroid covered group was $37.5 \%$ and steroid uncovered was $52.1 \%$.Incidence of RDS was significantly high in steroid uncovered group. In our study seven babies died in utero due to severe preeclampsia and its complications, 5 babies died in the neonatal period due to hypoxic ischaemic encephalopathy, RDS and septicaemia.

\section{Conclusion}

Anaemia, infections and severe preeclampsia are the most common etiological causes of preterm births. Prolongation of pregnancy for 48 hours in selected cases using Tocolytics and Antibiotics reduced neonatal morbidity due to RDS, where the benefit of steroid therapy was obtained. Preterm labour and preterm birth cannot be prevented but incidence can be reduced by proper and appropriate intervention.

\section{Funding: Nil, Conflict of interest: Nil Permission from IRB: Yes}

\section{References}

1. Vaahtera M, Kumala T,Ndekha M D,Koivisto AM, Cullinan T, Salin ML, Ashom. Antenatal and perinatal predictors of infant mortality in rural Malaw.Aechives of disease in childhood fetal and neonatal edition 2000; 82: 200-204

2. Fact sheet N 363, WHO Media centre (www WHO, Int/ media centre/factsheet/fs363)

3. Sayres WG Jr. Preterm labor. Am Fam Physician. 2010 Feb 15;81(4):477-84.

4. Harry M Georgiou, Megan. K.W. Di Quinzio, Michael permezel, Shaun. P Brennecke; Predecting Preterm Labor: Current status and future prospects; Disease Markers; $\mathrm{dx}$ doi.org/10.1155/2015/435014.

5. Martin JA, Kochanek KD, Strobino DM, Guyer B, MacDorman MF. Annual summary of vital statistics-2003. Pediatrics. 2005 Mar;115(3):619-34.

6. Roberts CL, Algert CS, Carnegie M, Peat B. Operative delivery during labour: trends and predictive factors. Paediatr Perinat Epidemiol. 2002 Apr;16(2):115-23.

7. American College of Obstetricians and Gynecologists; Committee on Practice Bulletins-Obstetrics. ACOG
Original Research Article

practice bulletin no. 127: Management of preterm labor. Obstet Gynecol. 2012 Jun;119(6):1308-17. doi: 10.1097/ AOG. 0b013e31825af2f0.

8. McPheeters ML, Miller WC, Hartmann KE, Savitz DA, Kaufman JS, Garrett JM, Thorp JM. The epidemiology of threatened preterm labor: a prospective cohort study. Am J Obstet Gynecol. 2005 Apr; 192(4):1325-9; discussion 1329-30.

9. Gonçalves LF, Chaiworapongsa T, Romero R. Intrauterine infection and prematurity. Ment Retard Dev Disabil Res Rev. 2002;8(1):3-13.

10. Lamont RF. Infection in the prediction and antibiotics in the prevention of spontaneous preterm labour and preterm birth. BJOG. 2003 Apr;110 Suppl 20:71-5.

11. Wright SP, Mitchell EA, Thompson JM, Clements MS, Ford RP, Stewart AW. Risk factors for preterm birth: a New Zealand study. N Z Med J. 1998 Jan 23;111 (1058):14-6.

12. Scholl TO, Hediger ML. Anemia and iron-deficiency anemia: compilation of data on pregnancy outcome. Am J Clin Nutr. 1994 Feb; 59 (2 Suppl):492S-500S discussion 500S-501S.

13. Samadi AR, Mayberry RM. Maternal hypertension and spontaneous preterm births among black women. Obstet Gynecol. 1998 Jun;91(6):899-904.

14. Juliar Warner Gargon, Claudia B Holzman,Patricia K. Senagore, M. Lynne Reuss; Evidence of placental haemorrhage and preterm delivery, British Journal of Obstetrics and gynaecology; 2010 March 117(4):445-455.

15. C. Holzman, B. Bullen, R. Fisher, N. Paneth, L. Reuss, Prematurity Study Group Pregnancy outcomes and community health: the POUCH study of preterm birth, DOI: 10.1046/j.1365-3016.2001.00014.x

16. Singh Uma, Singh Nisha, Seth Shikha. A prospective analysis of etiology and outcome of preterm labour. J Obstet Gynecol India. 2007;57(1):48-52.

17. Adewole IF .Prophylactic antibiotics for inhibiting preterm labour with intact membranes: RHL commentary (last revised: 15 November2002).The WHO Reproductive health library; Geneva: World Health Organisation.

18. C. Hubinont and F. Debieve. Review Article, Prevention of preterm labour:2011 Update on Tocolysis, Journal of pregnancy, volume 2011, Article ID 941057, 5.

\section{How to cite this article?}

Sunita Sudhir P, Mishra S. A Prospective study of etiology and outcome of Preterm Labour in a Rural Medical College. Obs Rev:J obstet Gynecol 2016;2(4):44-48.doi: 10.17511/joog.2016.i04.01. 